\title{
A novel class of zwitterionic gemini surfactants
}

\author{
Biswa B. Nayak, Sabita Patel, Pradipta K. Behera, and Bijay K. Mishra* \\ Centre of Studies in Surface Science and Technology, Department of Chemistry, Sambalpur \\ University, Jyoti Vihar 768019, India \\ E-mail: bijaym@hotmail.com
}

\begin{abstract}
Gemini surfactants with two methylene spacers from ethylenediamine tetraacetic acid and alkyl bromides have been synthesized and characterized from spectral data. The results of conductivity measurement leads to the proposition of micellar aggregates.
\end{abstract}

Keywords: Gemini surfactants, ethylenediamine tetraacetic acid, surfactants, micelle, quaternisation

\section{Introduction}

The hydrophile-lipophile balance (HLB) is an important characteristic of a molecule to behave as a surface active agent or surfactant. To illustrate, neither the teramethylammonium bromide nor the hexadecylammonium bromide behaves as a surfactant while hexadecyltrimethylamonium bromide behaves as a good surfactant capable of forming all types of aggregates i.e. micelle, reversed micelle, microemulsions etc. Substitution of one methyl group by another hexadecyl group increases the hydrophobicity thus perturbing the HLB and similarly, substituting another alkyl ammonium unit at the nitrogen function increases the hydrophilicity and thus does not behave as a god surfactant. However if two hexadecyltrimethyl ammonium ions are linked at the nitrogen centers by a small spacer, the molecule is called a gemini surfactant, the micellar properties change significantly. The behaviour of gemini surfactants in which two quaternary ammonium species $\left(\mathrm{C}_{12} \mathrm{H}_{25} \mathrm{~N}^{+}\left(\mathrm{CH}_{3}\right)_{2}{ }^{-}\right)$are linked at the head group by a hydrocarbon spacer $\left(\left(\mathrm{CH}_{2}\right) \mathrm{n}: \mathrm{n}=2,3,4\right)$ in aqueous medium have been investigated in details ${ }^{1-5}$ and the gemini surfactants are found to show significant changes in the surface activities from those of corresponding monomeric units. ${ }^{6,7}$ The critical micelle concentration values of these surfactants have been found to be 100 times less than the monomeric counterparts. ${ }^{8}$ Different aggregated structures due to gemini surfactants have also been reported. ${ }^{9}$

Some functionalized gemini surfactants behave as transfection vectors to introduce nucleic acid into eukaryotic cells. ${ }^{10}$ Saily et al. have synthesised the cationic gemini surfactant (2S,3R)- 
2,3-dimethoxy-1,4-bis( $N$-hexadecyl- $N, N$-dimethylammonium) butane dibromide and have shown this to be an efficient transfection vehicle. ${ }^{11}$

Recently Rist $e t a l^{12}$ have synthesised a series of molecules (1) each with two hydrophobic chains and oxyethylene groups as spacers as well as a part of hydrophilic groups, the other part being onium ions. However, they have considered these molecules as gemini surfactants. The hydrophilic group in these molecules may be considered as a single hydrophilic group and thus these molecules should be brought under double-tailed surfactants, which contain a single hydrophilic unit and two hydrophobic groups.

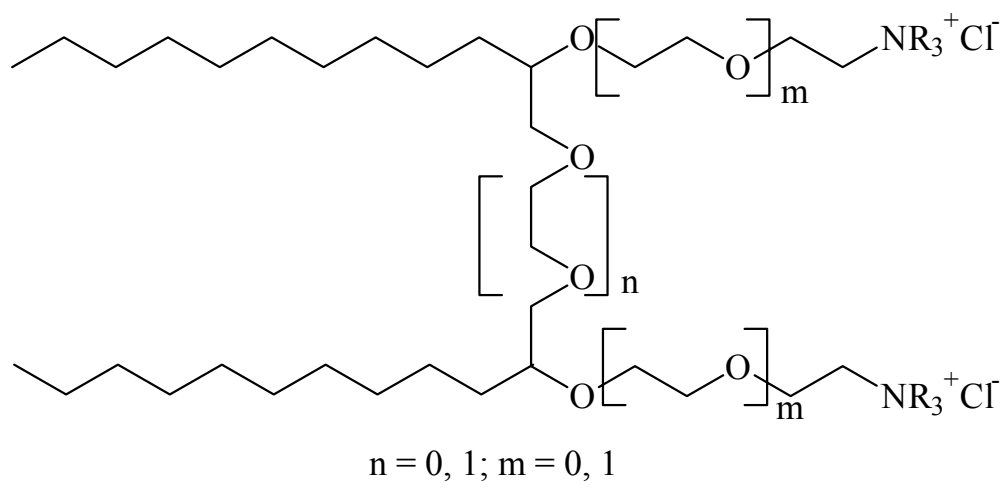

1

Synthesis of double tailed bisquaternary salts from pyridinium moieties have been reported by Pernak and Rogoza wherein the hydrophobic tail contains 8-12 methylene groups. ${ }^{13}$ However there is no mention on the solution behaviour of these compounds.

In the present work attempts have been made to synthesize some gemini surfactants with functionalized hydrophilic group and an ethylene hydrophobic spacer. The surfactants have zwitterionic head groups and carboxylic groups as the hydrophilic unit.

\section{Results and Discussion}

Ethylene diamine tetraacetic acid (EDTA) is known to be an efficient metal ion trapper and is used as an analytical reagent for estimation of various divalent metal ions. The reagent is highly water-soluble and thus ineffective to be used in nonpolar or lipid systems. The reagent has been made amphiphilic by attaching hydrophobic units to the molecule. When an equivalent mixture of disodium salt of ethylene diamine tetraacetic acid (EDTA-Na $)_{2}$ and alkyl bromide refluxed in acetonitrile in heterogeneous condition a single quaternised salt, $\mathrm{nN} 2 \mathrm{~N}$ (n stands for the number of carbon atom of the alkyl chain), $\mathbf{2}$, is obtained (Scheme-1).

The elemental analyses, IR and NMR spectral characteristics also support the structure of the compound to be the quaternised product due to a single EDTA-Na ${ }_{2}$ and a single alkyl bromide. Further quaternization of monoquaternised products with corresponding alkyl bromides 
resulted in formation of diquaternized products, $\mathrm{nN} 2 \mathrm{Nn}, 3$. The diquaternized products were also obtained by heating EDTA- $\mathrm{Na}_{2}$ in excess of alkyl bromide for 80 hours. The diquaternised products may be structurally considered as gemini surfactants while the monoquaternized products may behave as normal surfactants. The solubility of these compounds in water decreases with increasing hydrophobicity. Compounds $8 \mathrm{~N} 2 \mathrm{~N} 8$ and $16 \mathrm{~N} 2 \mathrm{~N} 16$ are found to be insoluble in water but soluble in chloroform medium.

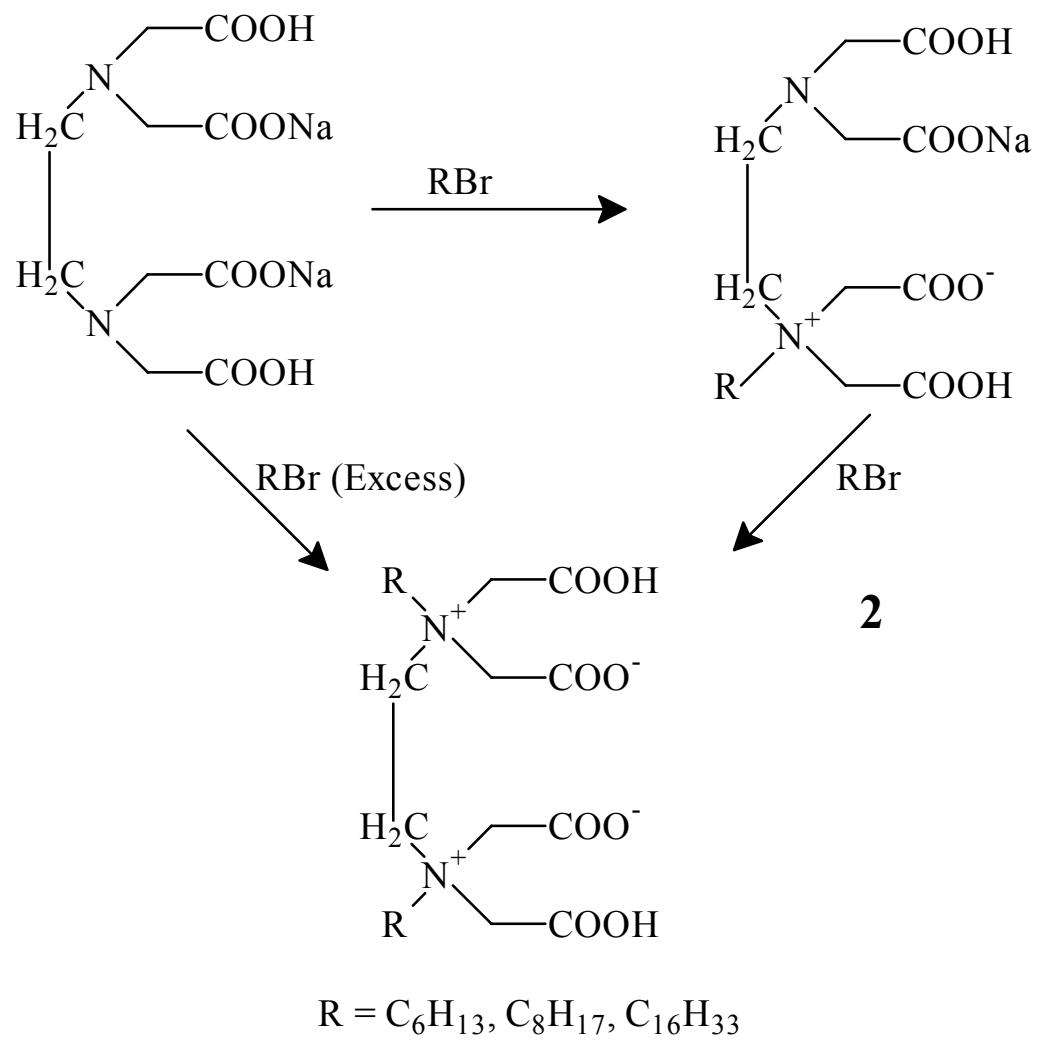

3

\section{Scheme 1}

The water-soluble compounds $(6 \mathrm{~N} 2 \mathrm{~N}, 6 \mathrm{~N} 2 \mathrm{~N} 6,8 \mathrm{~N} 2 \mathrm{~N}$ and $16 \mathrm{~N} 2 \mathrm{~N})$ were subjected to conductivity analyses. The plots of conductivity values at $28{ }^{\circ} \mathrm{C}$ versus the concentration of the compounds are found to be bilinear. At low concentration, the conductivity is low and increases with increasing concentration of the solute. Beyond a certain concentration, the conductivity increases sharply. The break in the linearity (Table 1) has been ascribed to the formation of micelle. The amphiphiles in monomer state behave as zwitterions with charge neutralization. However, in aggregated form, the amphiphiles produce an induced ionic field in the stern layer and the aggregates behave as multi-ionic species. Thus with increase in surfactants concentration 
the concentration of the aggregate increases and consequently the conductivity goes on increasing.

Table 1. Reaction condition and analytical characteristics of synthesized mono and diquaternized products

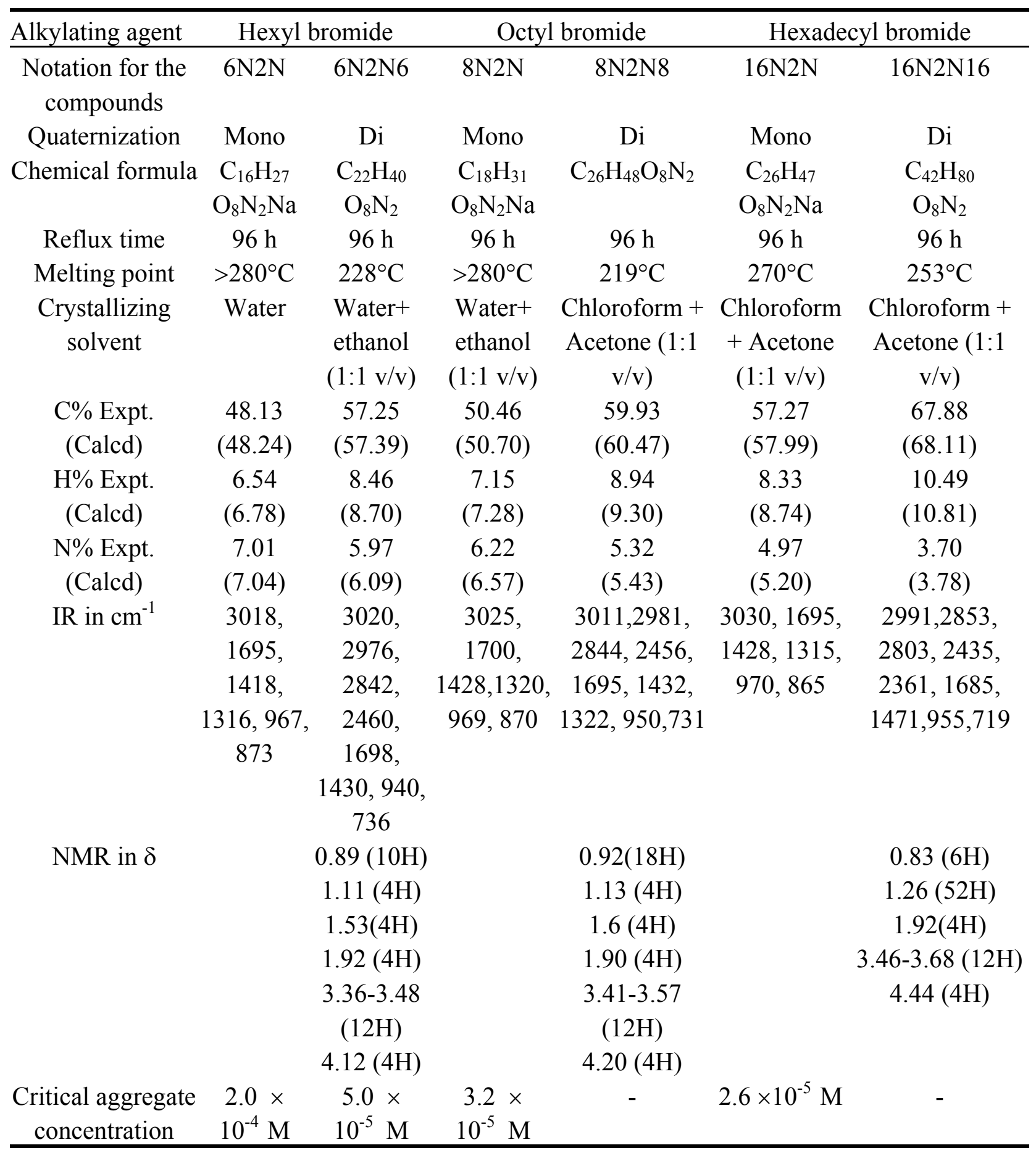


On addition of hexyl group to $6 \mathrm{~N} 2 \mathrm{~N}, 6 \mathrm{~N} 2 \mathrm{~N} 6$ is formed and the CMC of the compound is found to decrease significantly. Similarly $8 \mathrm{~N} 2 \mathrm{~N}$ and $16 \mathrm{~N} 2 \mathrm{~N}$ have low CMC values when compared to $6 \mathrm{~N} 2 \mathrm{~N}$. Due to less solubility of $8 \mathrm{~N} 2 \mathrm{~N} 8$ and $16 \mathrm{~N} 2 \mathrm{~N} 16$ in water, conductivity of these compounds could not be measured. These compounds may be capable of forming reversed micelles in non-aqueous medium.

\section{Experimental Section}

General Procedures. All chemicals and solvents applied were of synthesis quality unless otherwise stated. The alkyl bromides were from Fluka and the EDTA-Na $\mathrm{N}_{2}$ was obtained from Qualigens (India), (97-98\% purity). Melting points were obtained by open capillary method and uncorrected. Conductivites were recorded on a Systronics conductivity meter - MK-306 by using solution with triple distilled water. IR spectra were obtained with a Perkin Elmer FTIR spectrometer RX-1100 and NMR spectra were run on a Brucker MSL-90 spectrometer in $\mathrm{CDCl}_{3}$.

General Procedure for Monoquaternization of EDTA-Na 2 with Alkyl Bromides. A mixture of EDTA-Na $2(0.002 \mathrm{M}, 0.750 \mathrm{~g})$, alkyl bromide $(0.002 \mathrm{M})$ and acetonitrile $(20 \mathrm{ml})$ was refluxed in heterogeneous condition for 96 hours in an oil bath. The white solid compounds turned gray. It was filtered and washed with ether. The compound was crystallized from water or rectified spirit. General Procedure for Diquaternization of EDTA-Na 2 with Alkyl Bromides. A mixture of EDTA-Na $2(0.002 \mathrm{M}, 0.750 \mathrm{~g})$, alkyl bromide $(0.01 \mathrm{M})$ and acetonitrile $(20 \mathrm{ml})$ was refluxed in heterogeneous condition for 96 hours in an oil bath. A dark solid was obtained. It was washed with ether and chilled water for several times till the compound becomes gray. The gray compound was crystallized from ethanol/water or chloroform/acetone mixture. The reaction conditions and analytical parameters are given in Table 1.

\section{Acknowledgement}

The authors thank University Grants Commission and Department of Science and Technology, New Delhi for financial assistance through Departmental Research Support and FIST programme respectively.

\section{References}

1. Zana, R.; Benrraou, M.; Rueff, R. Langmuir 1991, 7,1072.

2. Zana, R.; Tamlon, Y. Nature 1993, 362, 228.

3. Tiecke, B. Langmuir 1998, 14, 800; 1999, 15, 391. 
4. Menger, F. M.; Keiper, J. S.; Azov, A. Langmuir 2000,16, 2062; Masugama, A.; Endo, C.; Takeda, S.; Nijima, M.; Ono, D.; Takeda, I. Langmuir 2000,16, 368.

5. Zana, R. In Special Surfactants, Robb, I. D., Ed.; 1997; Ch.4, 1997, p 81.

6. Rosen, M. J.; Mathias, J. H.; Davenport, L. Langmuir 1999, 15,7340.

7. Li, F.; Rosen, M. J. J Colloid Interface Sci. 2000, 224, 265.

8. Oda, K.; Huc, I.; Candau, S. Chem Commun. 1997, 2105.

9. Candau, S. Langmuir 1999, 15, 2384.

10. Fielden, M. L.; Perrin, C.; Kremer, A.; Bergsma, M.; Stuart, M. C.; Camilleri, P.; Engberts ,J. B. F. N. Eur. J. Biochem. 2001, 268, 1269.

11. Säily, M. J.; Ryhänen, S. J.; Holopainen, J. M.; Borocci, S.; Mancini, G.; Kinnunen, P. K. J. Biophys J, 2001, 81, 2135; Ryhänen, S. J.; Säily, M. J.; Paukku, T.; Borocci, S.; Mancini, G.; Holopainen, J. M.; Kinnunen, P. K. J. Biophysical Journal 2003, 84, 578.

12. Rist, O.; Rike, A.; Ljones, L.; Carlsen, P. H. J. Molecules 2001, 6, 979.

13. Pernak, J.; Rogoza, J. Arkivoc 2000, 1, 889. 